\title{
INVOLVEMENT OF CHOLESTEROL, PROGESTERONE, CORTISOL AND LIPOPROTEINS IN METABOLIC CHANGES DURING EARLY ONTOGENESIS OF BROILER CHICKS OF AN INDUSTRIAL CROSS
}

\section{E.A. KOLESNIK' ${ }^{1}$ M.A. DERKHO ${ }^{2}$}

\author{
${ }^{1}$ All-Russian Research Institute of Veterinary Sanitation, Hygiene and Ecology, Ural Branch, Federal Agency of Scien- \\ tific Organizations, 18A, ul. Sverdlovskii trakt, Chelyabinsk, 454106 Russia, e-mail evgeniy251082@mail.ru (corre- \\ sponding author); \\ ${ }^{2}$ South Ural State Agrarian University, 13, ul. Gagarina, Troitsk, Chelyabinsk Province, 457100 Russia, e-mail \\ derkho2010@yandex.ru
}

ORCID:

Kolesnik E.A. orcid.org/0000-0002-2326-651X

The authors declare no conflict of interests

Received January 8, 2017

Derkho M.A. orcid.org/0000-0003-3818-0556

\begin{abstract}
Morphophysiological changes in body are influenced by environmental factors, what is more, the specific nature of the body reactions depends on the reaction rate and the stage of ontogenesis on which the physiological stimuli act (I. Schmalhausen, 1982). Also it is known that hormones participate in the regulation of metabolism, growth and development, in adaptation processes. We determined the concentration of high-density (HDL) and low density (LDL) lipoproteins directly involved in protein and lipid metabolism, total cholesterol (TCS), progesterone $\left(\mathrm{P}_{4}\right), 17$ hydroxyprogesterone (17-OHP), and cortisol in blood plasma of Hubbard F15 broiler chickens at early postnatal ontogenesis using four groups of poultry of the industrial herd of Chebarkulskaya Ptitsa LLC (Chelyabinsk Province, Russian Federation), 10 animals in each, aged 1, 7, 23 and 42 days, respectively. The role and interrelations of these substances in metabolism were assessed using Pearson's correlation analysis and factor analysis by the principal components method with Varimax factor rotation. Thus, in 1-day aged chicks, the integration of factors HDL, LDL, TCS, $\mathrm{P}_{4}$ and cortisol involved in metabolic processes and metabolism regulations was noted with $r$-Pearson for $\mathrm{P}_{4}$ and Cortisol at $r=0.69, \mathrm{p}=0.027$; for $\mathrm{P}_{4}$ and TCS at $r=0.82, \mathrm{p}=0.004$; for HDL and LDL at $r=0.83, \mathrm{p}=0.003$; and for HDL and TCS at $r=-0.67, \mathrm{p}=0.033$. On day 7 day, the principal components were progesterone and cortisol ( $r$-Pearson for $\mathrm{P}_{4}$ and cortisol of $r=0.73, \mathrm{p}=0.016$ ), and a cholesterol donation factor with LDL and TCS as the leading elements $(r=0.73, \mathrm{p}<0.05)$. In 23-day-old chicks the components which have become principal were $\operatorname{HDL}(r=0.91, \mathrm{p}<0.05)$ and 17-OHP $(r=0.74, \mathrm{p}<0.05)$, which we attribute to growth, and also $\mathrm{P}_{4}(r=-0.88, \mathrm{p}<0.05)$ and cortisol $(r=-0.77, \mathrm{p}<0.05)$ viewed as regulatory ones. On day 42 we revealed cholesterol donation factor ( $r$-Pearson of $r=0.86, \mathrm{p}=0.002$ for LDL and TCS) and an integral factor with the principal components HDL $(r=0.74, \mathrm{p}<0.05), \mathrm{P}_{4}(r=0.76, \mathrm{p}<0.05)$ and cortisol $(r=0.84, \mathrm{p}<$ $0.05)$. Thus, here we described the age-specific features of interaction between lipoproteins and hormones of cholesterol-progesterone-cortisol system involved in broiler metabolism, and found out the change of principal components and functional relationships among the hormones of progesterone group and lipoproteins during early growth, which, according to our thought, makes a physiological basis for chicken performance under commercial poultry production. In further studies, it can be reasonable to assess the role of these hormones and metabolites in the control of reaction norm and adaptive capability of broilers, and the physiological cost of adaptation (i.e. adequate or pathological response) to reproduction at commercial farms.
\end{abstract}

Keywords: progesterone, 17-hydroxyprogesterone, cortisol, high density lipoproteins, low density lipoproteins, cholesterol, broiler chicks, early ontogenesis, homeostasis

It was I.I. Schmalhausen who noted that morphophysiological changes are directly related to the effect of environmental factors on the totality of development processes [1]. Body response to external actions becomes a kind of stimulus, which causes subsequent responses. Though, the specificity of the form-building reactions primarily depends on the organism itself, its norms of reaction and the stage of ontogenesis which is affected by the stimuli [1]. 
The homeostasis that consolidates the cycles of synthesis and decomposition of chemicals into the viable morphofunctional structure of the open system, the organism [2], can be defined as maintaining the relative dynamic constancy of the internal environment on the basis of interrelated systemic regulatory and metabolic processes involving endogenous and exogenous factors that determine ontogenetic development [3, 4]. Broiler chickens in their early neonatal period of development have critical stages, when physiological and biochemical mechanisms are being formed. These mechanisms ensure the sustainable performance and adaptive capabilities of the organism under intensive commercial poultry farming technologies [3, 5-7]. The endocrine regulation serves as the basis of homeostasis, formed during the species evolution, and as the primary link between endo- and exogenous flows of energy, substrates, and signaling pathways. It includes a hierarchical chain of hormones; the blood content of these hormones according to the type of feedback determines, among other things, the amount of blood cholesterol and lipoproteins, which reflect both the processes of synthesis of adrenal hormones and their regulatory effects [2, 8-10]. One of these hormones, the progesterone synthesized from low-density lipoprotein cholesterol, is best known for its participation in the endocrine control of the formation, growth and development of the fetus. 17-Hydroxyprogesterone is the main circulating metabolites of progesterone and one of the leading precursors of steroids $[11,12]$. Recent studies have established that progesterone and its synthetic derivatives have a direct, due to the neurosteroids of the group of pregnenolone synthesized de novo from cholesterol in the brain of birds [12], and mediated $[13,14]$ effects on the vegetative and central nervous system. They also participate in the neurotransmitter control over the chronological rhythms of postnatal growth and development due to receptor interaction with $\gamma$ aminobutyric acid [12,13] and dopamine, affect the organogenesis of blood vessels, locomotor apparatus [15], skeletal muscles (which has hypertrophic development in broiler chickens) [5, 9], and myelination of nerve fibers [13]. Progesterone, 17-hydroxyprogesterone and its metabolite cortisol are among the primary activators and effectors of the hypothalamic-pituitary-adrenal axis $[10,16]$. However, the information on the role of progesterone and its derivatives in lipid and protein metabolisms (despite the direct link between the biosynthesis of these metabolites, particularly the low and high density lipoproteins and hormones) is extremely limited. The available information is mainly obtained in medicine, whereas in livestock husbandry, where such studies are of great practical importance, the data are single, scattered or almost unavailable.

This paper is the first to report a systemic study of high and low density lipoproteins (directly involved in protein and lipid metabolism), total cholesterol, progesterone, 17-hydroxyprogesterone, cortisol in blood of Hubbard F15 cross chicks aged 1, 7, 23 and 42 days (with regard of growth and development), and to generalize these biochemical parameters by correlation analysis and the principal components (factor analysis). This resulted in finding age-related profiles of concentrations of these metabolic and regulatory factors that may reflect their changing roles during growth and adaptation.

Here, we studied dynamics of the blood content of some metabolites and hormones (lipoproteins, cholesterol, progesterone and its derivatives) in broilers in relation to changes in body weight, in order to assess the age-related changes of these factors and their role in ontogenesis.

Techniques. The experiments were carried out on broilers of the Hubbard F 15 cross (Chebarkul'skaya Ptitsa LLC, Chelyabinsk Province). The groups (P1, P7, P23, P42, $n=10$ each) were formed in the growing room (cage housing), the age of the bird by groups was 1, 7, 23 and 42 days, respectively. Feeding and 
housing were according to the zoo hygienic norms with unlimited feed access [17].

Blood samples were collected after decapitation at the age of 1 and 7 days, according to the principles of humanity set out in the directives of the European Community (86/609/EEC) and the Helsinki Declaration, and intravitally, in 23- and 42-day old chicks, by vacuum puncturing the axillary vein. In the plasma stabilized with EDTA, total cholesterol (TC), low-density lipoproteins (LDL), and high-density lipoproteins (HDL) were assessed by enzyme assays using commercial kits (Vektor-Best, Russia; Olveks Diagnostikum, Russia) [18, 19]. The hormones were determined by solid-phase enzyme-linked immunoassay (ELISA) using sandwich-type test systems (XEMA Co., Ltd, Russia), namely Progesterone-IFA K207 for progesterone (Pregn-4-ene-3,20-dione, $\mathrm{P}_{4}$ ) [20], 17$\mathrm{OH}$-Progesterone-IFA K217 for 17-hydroxyprogesterone (17-OHP) and Cortisol-IFA K210 for cortisol [11]. In the analysis of hormones, the samples were incubated in an ELMI Sky Line Shaker ST-3 thermostate shaker (ELMI, Ltd, Latvia). The absorbency was measured on a photometer for MINDRAY MR96A Elisa Microplate Reader (MINDRAY Ltd, PRC).

The average daily body weight gain for the age periods was calculated as follows: $A_{a d b w g}=\left(\mathrm{W}_{1}-\mathrm{W}_{0}\right) /\left(\mathrm{T}_{1}-\mathrm{T}_{0}\right)$, where $\mathrm{W}_{0}$ and $\mathrm{W}_{1}$ are the body weight $(\mathrm{g})$ at the beginning and the end of the period studied at the age $T_{0}$ and the subsequent age $T_{1}$ (days).

To identify the structure of the relationships of the analyzed elements, the Pearson correlation (r-Pearson) analysis and factor analysis [21] for normal distribution of the biochemical parameters (STATISTICA 8.0, StatSoft, Inc., USA) were performed. The factors were isolated by the principal components method, Varimax method was used for the factor rotations [21]. The numerical data is represented by the arithmetic mean $(X)$ and standard mean error $( \pm \mathrm{SEM})$. The degree and reliability of the differences for the results obtained were evaluated by the Student's $t$-test using STATISTICA 8.0 software. Differences were considered statistically significant at $\mathrm{p} \leq 0.05$.

Results. By day 7, the curves of dynamics of the TCS and lypoprotein

1. Dynamics of blood biochemical parameters and body weight in Hubbard F15 cross broiler chickens in early postnatal ontogenesis ( $X \pm \mathrm{SEM}, n=10$, Chebarkul'skaya ptitsa, LLC, Chelyabinsk Province, 2014)

\begin{tabular}{|c|c|c|c|c|}
\hline \multirow{2}{*}{ Показатель } & \multicolumn{4}{|c|}{ Возраст, сут } \\
\hline & $1-\mathrm{e}$ & $7-\mathrm{e}$ & $23-и$ & $42-\mathrm{e}$ \\
\hline High density lipoproteins, mmol/1 & $1.79 \pm 0.04$ & $1.17 \pm 0.03 * * *$ & $1.36 \pm 0.05^{* * *}$ & $1.69 \pm 0.04$ \\
\hline Low density lipoproteins, mmol/1 & $5.68 \pm 0.27$ & $1.39 \pm 0.28 * * *$ & $1.81 \pm 0.16^{* * *}$ & $2.32 \pm 0.13^{* * *}$ \\
\hline Total cholesterol, $\mathrm{mmol} / \mathrm{L}$ & $8.67 \pm 0.57$ & $3.14 \pm 0.25^{* * *}$ & $4.65 \pm 0.32 * * *$ & $4.84 \pm 0.14^{* * *}$ \\
\hline Progesterone, nmol/1 & $63.00 \pm 3.59$ & $65.28 \pm 2.20$ & $57.13 \pm 2.40$ & $51.07 \pm 4.28$ \\
\hline 17-hydroxyprogesterone, nmol/1 & $10.76 \pm 1.61$ & $19.43 \pm 3.40^{*}$ & $17.87 \pm 3.36^{*}$ & $8.30 \pm 1.42$ \\
\hline Cortisol, nmol/1 & $2274.31 \pm 59.47$ & $2341.42 \pm 44.29$ & $2351.38 \pm 35.37$ & $2256.00 \pm 45.18$ \\
\hline Average daily body weight gain, g/day & & $16.37 \pm 0.21$ & $49.98 \pm 0.11^{* * *}$ & $79.28 \pm 1.05^{* * *}$ \\
\hline
\end{tabular}

concentrations were parallel to the graphics of reduction in HDL level up to $34.64 \%$ ( $p<0.001)$, in LDL level up to $75.53 \%(\mathrm{p}<0.001)$, and in cholesterol up to $63.78 \%(\mathrm{p}<0.001)$ (Table 1$)$. From day 23 , a gradual increase and stabilization of the amount of total sterol and lipoproteins occurred. However, the greatest approximation of HDL content to the value in the group of a dayold chicks was at the age of 42 days (see Table 1). The changes in the progesterone and cortisol levels were unreliable. The graphics of cortisol and its precursor progesterone concentrations (Cortisol and $\mathrm{P}_{4}$ ) were inversely symmetric to the curves for HDL, LDL and TCS, with relatively high values from 7 to 23 days of life (see Table 1). The dynamics of 17-OHP concentration and body weight gain in broiler chickens had a significant similarity to the peak of max- 
imum values at the age of 7-23 days. The average daily body weight gain was the largest in 23 day-old chicks, $305.32 \%$ ( $p<0.001$ ) (see Table 1). Except the HDL, the 17-OHP content at day 42 of life was restored to that at the age of 1 day, and the absolute value of the daily body weight gain from days 23 to 42 was the highest $(158.62 \%, \mathrm{p}<0.001)$, although remaining below the reference one which was registered from day 7 to day $23(305.32 \%, p<0.001)$ (see Table 1).

We calculated the mutual correlations (including the Pearson correlations) and determined factors and corresponding principal components among the studied biochemical indicators at different periods of broiler growth and development (Table 2).

2. Factor analysis with principal component method of blood biochemical parameters in Hubbard F15 cross broiler chickens in early postnatal ontogenesis

\begin{tabular}{|c|c|c|c|c|c|c|c|}
\hline \multirow{4}{*}{ Parameter } & \multicolumn{7}{|c|}{ Age, days } \\
\hline & 1 & \multicolumn{2}{|c|}{7} & \multicolumn{2}{|c|}{23} & \multicolumn{2}{|c|}{42} \\
\hline & \multicolumn{7}{|c|}{ factor } \\
\hline & 1 & 1 & 2 & 1 & 2 & 1 & 2 \\
\hline \multicolumn{8}{|l|}{ Lipoproteins: } \\
\hline high density & $0.80^{*}$ & 0.07 & 0.66 & $0.91^{*}$ & 0.07 & -0.40 & $0.74^{*}$ \\
\hline low density & $0.83^{*}$ & 0.40 & $0.73^{*}$ & 0.68 & 0.29 & $0.97 *$ & -0.03 \\
\hline Total cholesterol & $-0.88^{*}$ & -0.17 & $0.73^{*}$ & -0.53 & 0.06 & $0.89^{*}$ & -0.24 \\
\hline Progesterone & $-0.88^{*}$ & $0.91^{*}$ & -0.17 & -0.26 & $-0.88^{*}$ & 0.20 & $0.76^{*}$ \\
\hline 17-Hydroxyprogesterone & -0.60 & 0.62 & 0.25 & $0.74^{*}$ & -0.55 & 0.66 & 0.39 \\
\hline Cortisol & $-0.74 *$ & $0.88^{*}$ & 0.31 & 0.34 & $-0.77 *$ & -0.11 & $0.84^{*}$ \\
\hline
\end{tabular}

N ot e. Factors rotation by Varimex method. Correlations and the principal components were calculated and determined for each identified factor.

* Correlations are statistically significant at $\mathrm{p}<0.05$.

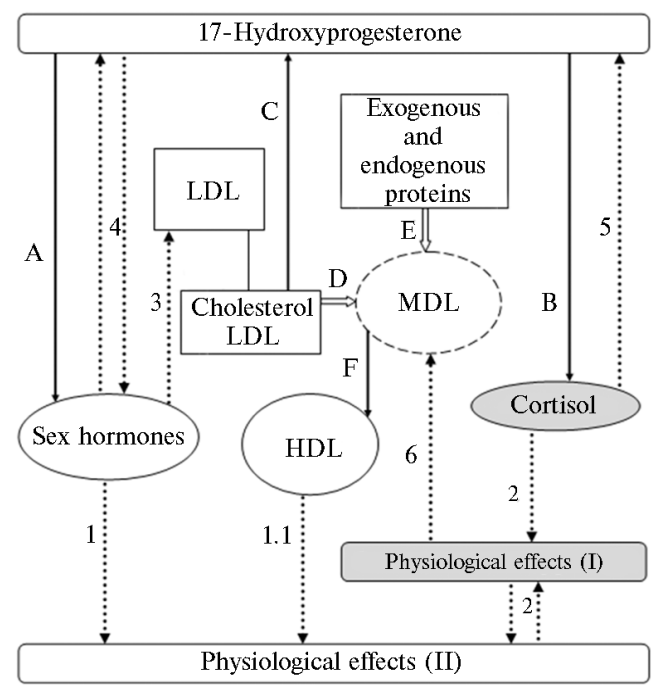

The scheme showing the involvement of cholesterol, progesterone, cortisol, and lipoproteins in growth and development of Hubbard F15 broiler chickens: LDL - low density lipoproteins, MDL - medium density lipoproteins, HDL high density lipoproteins; A, B and C - the synthesis of sex hormones, cortisol and 17hydroxyprogesterone, respectively; D, E and $\mathrm{F}$ - conversion of low density lipoproteins and proteins to high density lipoproteins; 1 and 1.1 - regulation to provide growth and development with structural proteins, $2-$ mutual regulation of adaptation, growth and development, 3 - regulation of LDL metabolism, 4 regulation of 17-hydroxyprogesterone and sex hormone metabolism, 5 - regulation of 17 hydroxyprogesterone metabolism, 6 - regulation of HDL synthesis. Solid lines mark biosynthetic processes, and dotted lines mark regulation of biosynthetic processes.

The method of principal components revealed one common factor in 1day old broiler, and there were two factors for each of periods from day 7 to day 23 and from day 23 to day 42 of life (see Table 2). The results we obtained and published data allow us to propose a generalized pattern of the studied hormone and metabolite interactions (Fig.). Here, the processes are divided into synthetic and regulatory ones, and their effects appear sequentially. At any current stage of development, a physiological and biochemical platform is formed (these processes we designate as adaptive; physiological effects I), which provides growth and development in the next stage (physiological effects II). Based on the data from the Table 2 and the scheme, the factors that were allocated for each of the studied 
periods included the principal components which we mainly considered as adaptive and growth factors, or as an aggregate factor combining components with adaptive and growth functions (see Table 2, Fig.). Thus, in a day-old chicks, there was an integrative factor of metabolic and adaptive processes that included hormonal and metabolic components (see Table 2). This characterizes their significant relationship (r-Pearson: $\mathrm{P}_{4}$ and Cortisol $-r=0.69, \mathrm{p}=0.027 ; \mathrm{P}_{4}$ and TCS $-r=0.82, \mathrm{p}=0.004$; HDL and LDL $-r=0.83, \mathrm{p}=0.003$; HDL and TCS $-r=-0.67, \mathrm{p}=0.033$ ) in the earliest postnatal period, when the metabolism is still not fully formed [3, 5, 6, 9], and reflects the strength in all functional systems during transition from prenatal to postnatal stage and also the impact of environmental factors [22]. This determines the homeostatic parameters that ensure de novo formation of structural and energy resources for subsequent growth and development (see Table 2, Fig.) [3, 9, 23]. On day 7, the broilers showed a factor (see Table 2, Fig.) which included progesterone and cortisol as principal components ( $\mathrm{r}-\mathrm{Pearson}: \mathrm{P}_{4}$ and Cortisol $-r=0.73, \mathrm{p}=0.016$ ), and also a factor of cholesterol donation through active conversion of LDL cholesterol to progesterone and, therefore, the activation of endocrine metabolic pathway of 17-OHP and its products, the sex hormones, cortisol and other steroids $[15,16]$ (see Table 1, 2, Fig.). Progesterone (along with somatotropic and thyroid hormones) provides an increase in body weight, primarily due to the regulation of the synthesis of proteins (mainly the proteins of skeletal muscles and tissues of internal organs) [24]. Progesterone affects metabolism and increases its intensity in chicks. Cortisol directly participates in complex adaptive responses at molecular, membrane, cellular, tissue, and organ levels [10, 16]. Cortisol (see Fig.) also systemically strengthens or weakens adaptive responses, depending on the "expenses" for adaptation and the stage of ontogenesis, and regulates 17OHP metabolism [25]. It is known that estrogens and other hormonal products of 17-hydroxyprogesterone normally promote utilization of LDL, enhance HDL synthesis, and are involved in synthesis of structural substances necessary for body growth and development [24, 26-28] (see Fig.).

At the age of 23 days, chickens showed two factors. One included HDL and 17-OHP, the other one comprises progesterone and cortisol (see Table 2), which agrees with the data of S. Rettenbacher et al. [29]. These authors showed that an increase in the glucocorticoid content due to stress or exogenous experimental impact (for example, glucocorticoid administration to intact chickens) can lead to a decrease in the conversion of progesterone to 17-OHP and its derivatives due to inhibition of specific enzymes (e.g. 17 $\alpha$-hydroxylase, 17,20-lyase, $17 \mathrm{p}$-hydroxysteroid dehydrogenase) or competitive interaction of glucocorticoids with nuclear and membrane progesterone receptors involved in regulation of expression of the glucocorticoid-synthesizing enzymes [29]. At the same time, in incubated in vitro ovarian tissues of female chickens and testicles of males (i.e. without exogenous stress impact), glucocorticoids do not interfere with the progesterone transformation into 17-OHP and then into androstenedione, testosterone and other steroid products [29]. It was shown [30] that stress inhibits the enzyme responsible for the conversion of cholesterol to pregnenolone. Moreover, as it was noted by us (see Table 1), progesterone, like cortisol, had stable dynamics with a statistically unreliable difference in content from day 7 to day 42 . The peaks of 17-OHP and body weight gain, vice versa, reliably occurred at the period from day 7 to day 23 (see Table 1). Achieving a balance of intensive adaptive and growth responses is based on high resource consumption, and may be the most apparent at the beginning of the formation of functional systems [3, $22,31]$. Thus, in the egg-type chickens, the greatest body weight gain was ob- 
served in the decades II and III [8] that agrees with our data (see Table 1). The cholesterol donation detected at the age of 42 days (see Table 2) (r-Pearson: LDL and TCS $-r=0.86, \mathrm{p}=0.002$ ) apparently provides an endocrine pool for the synthesis of progesterone and its derivatives [15, 16, 25] (see Table 1, 2, Fig.). It was reported [8] that in white Leghorn cross chicks the growth stabilized after 30 days of life. In this study, the principal components, revealed when the chicks aged 42 days (see Table 2), reflect stabilization and consolidation of adaptive and growth processes during the decade IV-the beginning of the decade $\mathrm{V}$ of the birds' life.

These complex interactions are aided by the hormones of the progesterone axis $[14,28]$, including glucocorticoids. There is a modulation of the lipoproteins metabolism and the implementation of their physiological effects [28] (see Fig.), particularly, the vascular ones. The events involve intracellular nuclear receptors [14] and the so-called extragenome integral membrane progesterone receptors $[14,15]$, involved in express responses not accompanied by gene transcription [14, 15], and, apparently, being necessary in growth and development.

Thus, in the whole, the data we obtained indicate that during the growth and development of chicks, the rate of cholesterol used for biosynthesis of steroid hormones changes. It affects the blood concentrations of lipoproteins and hormones, as well as their correlation. The age of chicks and, respectively, the nature of physiological processes in their body, including those mediated by progesterone, 17-hydroxyprogesterone and cortisol, determine formation of homeostasis which provides the development of resistance to the physiological states caused by technological stresses. The research may be continued to assess the role of these hormones and metabolites in determining the response patterns and the adaptive capabilities of broilers, and the body resources consumed for adaptation to the factors of intensive reproduction that, in turn, is related to the boundaries of the norm and pathology.

\section{REFEREN C ES}

1. $\mathrm{Sh}$ m a l' g a u z e n I.I. Organizm kak tseloe $v$ individual'nom i istoricheskom razvitii. Izbrannye trudy [Body as a whole in the course of individual and historical development. Selected works]. Moscow, 1982 (in Russ.).

2. Ku la e v B.S. Evolyutsiya gomeostazisa $v$ biologicheskom prostranstve-vremeni /Pod redaktsiei L.M. Chailakhyana [Evolution of homeostasis in biological space and time. L.M. Chailakhyan (ed.). Moscow, 2006 (in Russ.).

3. Kolesnik E.A., D e rk ho M.A. Problemy biologii produktivnykh zhivotnykh, 2015, 4: 72-81 (in Russ.).

4. Khoch a chka P., S o me ro Dzh. Biokhimicheskaya adaptatsiya [Biochemical adaptation]. Moscow, 1988 (in Russ.).

5. Te rte ry a n E.E. Materialy IV s"ezda Armyanskogo fiziologicheskogo obshchestva im. L.A. Orbeli [Proc. IV Conf. of L.A. Orbeli Armenian Physiological Society]. Erevan, 1987: 320 (in Russ.).

6. Fis i n i n V.I., S u r a i P. Ptitsevodstvo, 2012, 2: 11-15 (in Russ.).

7. Peng Y.Z., Wang Y.W., Ning D., Guo Y.M. Changes of haematic parameters, redox status and mitochondrial complex activity in the heart and liver of broilers fed with different density diets under low ambient temperature. Avian Pathology, 2013, 42(4): 327-334 (doi: 10.1080/03079457.2013.800941).

8. Terteryan E.E., Grigoryan M.S, Abramyan G.E., Manukyan S.S. Tezisy $X V$ s"ezda Vsesoyuznogo fiziologicheskogo obshchestva im. I.P. Pavlova (Kishinev, 1987) [Proc. XV Conf. of I.P. Pavlov All-Union Physiological Society, Kishinev, 1987]. Leningrad, 1987, V. 2: 595 (in Russ.).

9. Kolesnik E.A., Derkho M.A. Veterinariya, 2014, 7: 47-51 (in Russ.).

10. Wan Y., M a C., We i P., Fang Q., Gu o X., Z h o u B., Ji a ng R. Dynamic expression of HSP90B1 mRNA in the hypothalamus of two Chinese chicken breeds under heat stress and association analysis with a SNP in Huainan chickens. Czech. J. Anim. Sci., 2017, 62(2): 82-87 (doi: 10.17221/8/2016-CJAS). 
11. Gröschl M., Rauh M., Dör r H.G. Circadian rhythm of salivary cortisol, 17-OHprogesterone, and progesterone in healthy children. Clinical Chemistry, 2003, 49(10): 1688-1691 (doi: $10.1373 / 49.10 .1688$ ).

12. Ts u t s u i K. Neurosteroid biosynthesis and function in the brain of domestic birds. Frontiers in Endocrinology, 2011, 2(37): 1-14 (doi: 10.3389/fendo.2011.00037).

13. Pamir E., Ali D., Ismail C., Sanli E., Ali K., Mustafa T. The effects of high dose progesterone on neural tube development in early chick embryos. Neurology India, 2006, 54(2): 178-181.

14. S mith J.L., Kupchak B.R., Garita o nandia I., Hoang L.K., Maina A.S., R e galla L.M., L y o ns T.J. Heterologous expression of human mPRalpha, mPRbeta and mPRgamma in yeast confirms their ability to function as membrane progesterone receptors. Steroids, 2008, 73: 1160-1173 (doi: 10.1016/j.steroids.2008.05.003).

15. Voican A., Francou B., Novac L., Chabbert-Buffet N., Canonico M., Meduri G., Lombes M., Scarabin P.-Y., Young J., Guiochon-Mantel A., B o u lig a nd J. Pharmacology of hormone replacement therapy in menopause. In: Pharmacology. L. Gallelli (ed.). INTECH, 2012: 313-338 (doi: 10.5772/32655).

16. Hough D., Swart P., Cloe te S. Exploration of the hypothalamic-pituitary-adrenal axis to improve animal welfare by means of genetic selection: lessons from the South African merino. Animals, 2013, 3: 442-474 (doi: 10.3390/ani3020442).

17. Rekomendatsii po kormleniyu sel'skokhozyaistvennoi ptitsy /Pod redaktsiei V.I. Fisinina, Sh.A. Imangulova, I.A. Egorova, T.M. Okolelovoi [Poultry feeding - guide. V.I. Fisinin, Sh.A. Imangulov, I.A. Egorov, T.M. Okolelova (eds.)]. Sergiev Posad, 2004 (in Russ.).

18. Titov V.N., Vostrov I.A., Kaba S.I., A melyushkina V.A., Shiryae v a Yu.K. Klinicheskaya meditsina, 2013, 1: 20-27 (in Russ.).

19. B rai n e k P., Trub nik ova T.Yu. Pryamye metody opredeleniya kholesterina lipoproteidov vysokoi $i$ nizkoi plotnosti. Printsipy $i$ analiticheskie kharakteristiki [Direct methods of HDL and LDL cholesterol analysis. Principles and analytical parameters]. Erba Lachema s.r.o., Brno, 2015 (in Russ.).

20. De Geyter C., De Geyter M., Huber P.R., Nieschlag E., Holzgreve W. Progesterone serum levels during the follicular phase of the menstrual cycle originate from the crosstalk between the ovaries and the adrenal cortex. Hum. Reprod., 2002, 17(4): 933-939.

21. S y c h e v S.N. Sorbtsionnye i khromatograficheskie protsessy, 2004, 4(2): 134-143 (in Russ.).

22. Cogburn L.A., Porter T.E., Duclos M.J., Simon J., Burgess S.C., Zhu J.J., Cheng H.H., Dodgs on J.B., Burnside J. Functional genomics of the chicken - a model organism. Poultry Sci., 2007, 86(10): 2059-2094 (doi: 10.1093/ps/86.10.2059).

23. S u r a i P.F. Antioxidant systems in poultry biology: heat shock proteins. Journal of Science, 2015, 5(12): 1188-1222.

24. Brehme U., Bruck B., Gugel N., Wehrmann M., Hanke S., Finking G., $\mathrm{Schmahl}$ F.W., Hanke H. Aortic plaque size and endometrial response in cholesterol-fed rabbits treated with estrogen plus continuous or sequential progestin. Arteriosclerosis, Thrombosis, and Vascular Biology, 1999, 19: 1930-1937 (doi: 10.1161/01.ATV.19.8.1930).

25. Rettenbacher S., Möstl E., Groothuis T.G.G. Gestagens and glucocorticoids in chicken eggs. General and Comparative Endocrinology, 2009, 164: 125-129 (doi: 10.1016/j.ygcen.2009.05.019).

26. $\mathrm{S} \mathrm{chwe} \mathrm{n} \mathrm{k} \mathrm{e} \mathrm{D.C.} \mathrm{Gender} \mathrm{differences} \mathrm{in} \mathrm{intima-media} \mathrm{permeability} \mathrm{to} \mathrm{low-density} \mathrm{lipoprotein}$ at atherosclerosis-prone aortic sites in rabbits. Lack of effect of 17 beta-estradiol. Arteriosclerosis, Thrombosis, and Vascular Biology, 1997, 17(10): 2150-2157.

27. Hanke H., Hanke S., Finking G., Muhic-Lohrer A., Mück A.O., Schmahl F.W., $\mathrm{H}$ a a s is R., Ho m b a h V. Different effects of estrogen and progesterone on experimental atherosclerosis in female versus male rabbits. Quantification of cellular proliferation by bromodeoxyuridine. Circulation, 1996, 94(2): 175-181 (doi: 10.1161/01.CIR.94.2.175).

28. M c Crohon J.A., N a k h la S., J e s s u p W., S t a n l e y K.K., C e le r maje r D.S. Estrogen and progesterone reduce lipid accumulation in human monocyte-derived macrophages a sex-specific effect. Circulation, 1999, 100: 2319-2325 (doi: 10.1161/01.CIR.100.23.2319).

29. Rettenbacher S., Henriksen R., Groothuids T.G., Lepschy M. Corticosterone metabolism by chicken follicle cells does not affect ovarian reproductive hormone synthesis in vitro. General and Comparative Endocrinology, 2013, 184: 67-74 (doi: 10.1016/j.ygcen.2012.12.013).

30. S tojk ov N.J., J a nji c M.M., Bjel ic M.M., Mihajlovic A.I., Kostic T.S., A n d r i c S.A. Repeated immobilization stress disturbed steroidogenic machinery and stimulated the expression of cAMP signaling elements and adrenergic receptors in Leydig cells. Am. J. Physiol. Endocrinol. Metab., 2012, 302: E1239-E1251 (doi: 10.1152/ajpendo.00554.2011).

31. K o l e s n i k E.A., D e r k h o M.A. About cluster system of phospholipids in ontogenesis of broiler chickens. Sel'skokhozyaistvennaya biologiya [Agricultural Biology], 2015, 50(2): 217-224 (doi: 10.15389/agrobiology.2015.2.217eng). 